\title{
O contexto escolar dialogando com microterritorialidades urbanas: possibilidades includentes
}

\section{The school context in dialogue with urban micro territorialities: inclusive opportunities}

\author{
Carlos Henrique de Oliveira Aigner \\ carlosaigner@ig.com.br \\ Rede Municipal de Ensino de Porto Alegre \\ Cláudia Luísa Zeferino Pires \\ claudia.luisapires@gmail.com \\ Universidade Federal do Rio Grande do Sul
}

\begin{abstract}
Resumo: Este artigo trata de algumas reflexões sobre duas importantes abordagens conceituais no contexto da escola: cotidiano e microterritorialidade. Estes conceitos buscam auxiliar a compreensão da organização socioespacial no e do espaço e como estas contribuem para a valorização e construção de saberes e práticas de sujeitos e espaços sociais. Apresenta uma discussão em torno do papel da escola e do ensino de geografia numa lógica que tenta se contrapor à padronização e generalização de conteúdos, práticas e conceitos. Pretende posicionar, a partir dos educandos, outros olhares sobre a dinâmica espacial, especificamente, sob diferentes formas de sociabilidade do espaço urbano, a partir de suas vivências no e com o espaço na tentativa de dialogar com seu próprio conhecer e possibilitar diferentes formas de participação na sociedade.
\end{abstract}

Palavras-chave: Escola. Cotidiano. Microterritorialidade

\begin{abstract}
This article discusses some thoughts about two important conceptual approaches within the context of school: daily life and micro territoriality. Those concepts can be used to understand the socio-spatial organization in and with the space and how they contribute to the development and construction of knowledge as well as practices of individuals and social spaces. It presents a discussion about the school role and Geography teaching following the logic which tries to confront the standardization and generalization of contents, practices and concepts. This research aims to place, from students' eyes, other perspectives on the spatial dynamics, specifically under different forms of urban space sociability, from their own experience with and in the space, all in an attempt of a dialogue with their own knowledge and to enable different forms of participation in society.
\end{abstract}

Keywords: School. Daily life. Micro territoriality.

Resumen: Este artículo trata de algunas reflexiones sobre dos importantes enfoques conceptuales en el contexto escolar: el cotidiano y la micro territorialidad. Estos conceptos buscan auxiliar a la comprensión de la organización socio espacial en y del espacio y como estas contribuyen a la valorización y construcción de los saberes y prácticas de los sujetos y espacios sociales. Se presenta una discusión sobre el papel de la escuela y el enseño de Geografía en una lógica que intenta se contraponer a la estandarización y generalización de los contenidos, prácticas y conceptos. Se pretende 
posicionar, a partir de los estudiantes, otras perspectivas sobre el espacio urbano, a partir de sus vivencias no y con el espacio en el intento de dialogar con su propio conocer y posibilitar diferentes formas de participación en la sociedad.

Palabras clave: Escuela, Cotidiano, Micro territorialidad.

\section{INTRODUÇÃO}

As análises apresentadas e as reflexões, neste artigo, foram construídas a partir de vivências em escola municipal do bairro Restinga, Porto Alegre/RS. Trata-se de um bairro que possui uma autenticidade territorial que expressa diferentes apropriações espaciais a partir das relações de convivência e de redes cotidianamente estabelecidas que explicita uma totalidade complexa. A Restinga reflete a fragmentação urbana, o desenvolvimento desigual e a formação de espaços segregados dentro de um bairro quase que excluído do município, pelo menos em sua origem. Apresenta, atualmente, uma identidade urbana singular que foi se constituindo, ao longo de seu desenvolvimento de forma bem diversificada.

Essa discussão revela o quanto diferentes formas de apropriação territorial constituem-se em um movimento contínuo e que ao longo deste percurso vão produzindo pluralidades territoriais, cujas representações revelam a multiplicidade espacial produzida nos territórios cotidianos derivando novas relações sociais e culturais. Refletir sobre o acontecer no espaço remete a outra questão importante: a escala. Esta, neste relato, não trata de uma referência sobre planos cartesianos, mas sobre uma relação na perspectiva do sujeito e seu cotidiano, compreendido, também, na sua conexão com o mundo.

Nesse sentido, procura-se refletir sobre o cotidiano territorializado ${ }^{1}$ no bairro e suas possibilidades conceituais para o ensino de geografia. $\mathrm{O}$ entendimento de microterritorialidades perpassa pelas peculiaridades espaciais e por identidades que promovem a inserção dos sujeitos no bairro e também na cidade. Entende-se que essa dinâmica deve ser compreendida a partir de diferentes escalas temporais e espaciais, incluindo a dinâmica local/regional/global, relacionando com a apropriação espacial em diferentes realidades sociais. Com relação à construção de identidades, entretanto, é interessante refletir sobre alguns aspectos desse conceito. Kathryn Woodward (2005) faz algumas contextualizações importantes:

1. Precisamos de conceitualizações. Para compreendermos como a identidade funciona, precisamos conceitualizá-la e dividi-la em suas diferentes dimensões.

2.Com freqüência, a identidade envolve reivindicações essencialistas sobre quem pertence e quem não pertence a um determinado grupo identitário, nas quais a identidade é vista como fixa e imutável.

1 O cotidiano territorializado, neste artigo, representa a ideia de Michel Maffesoli (1991) que no âmago de "pequenas tribos", a realidade social privilegia a proximidade, a vida cotidiana, onde o "consenso", isto é, a partilha de sentimentos está centrada na relação de "proxemia", ou seja, a vida social é constituída por um sentido de pertença que tem suas regras de conduta e modo de vida, constituindo, assim a relação entre território e cotidiano. 
3.Algumas vezes essas reivindicações estão baseadas na natureza; por exemplo, em algumas versões da identidade étnica, na raça e nas relações de parentesco. Mais frequentemente, entretanto, essas reivindicações estão baseadas em alguma versão essencialista da história e do passado, na qual a história é construída ou representada como uma verdade imutável.

4. A identidade é, na verdade, relacional, e a diferença é estabelecida por uma marcação simbólica relativamente a outras identidades (na afirmação das identidades nacionais, por exemplo, os sistemas representacionais que marcam a diferença podem incluir um uniforme, uma bandeira nacional ou mesmo os cigarros que são fumados).

5. A identidade está vinculada também a condições sociais e materiais. Se um grupo é simbolicamente marcado como inimigo ou como tabu, isso terá efeitos reais porque o grupo será socialmente excluído e terá desvantagens materiais.

6. O social e o simbólico referem-se a dois processos diferentes, mas cada um deles é necessário para a construção e manutenção das identidades. A marcação simbólica é o meio pelo qual damos sentido a práticas e relações sociais, definindo, por exemplo, quem é excluído e quem é incluído. Por meio da diferenciação social que essas classificações da diferença são vividas nas relações sociais.

7. A conceitualização da identidade envolve o exame dos sistemas classificatórios que mostram como as relações sociais são organizadas e divididas; por exemplo, ela é dividida em ao menos dois grupos em oposição - "nós e eles".

8. Algumas diferenças são marcadas, mas nesse processo algumas diferenças podem ser obscurecidas; por exemplo, a afirmação da identidade nacional pode omitir diferenças de classe e diferenças de gênero.

9. As identidades não são unificadas. Pode haver contradições no seu interior que têm que ser negociadas; por exemplo, o miliciano sérvio parece estar envolvido em uma difícil negociação ao dizer que os sérvios e os croatas são os mesmos e, ao mesmo tempo, fundamentalmente diferentes.

10. Precisamos, ainda, explicar por que as pessoas assumem suas posições de identidade e se identificam com elas. Por que as pessoas investem nas posições que os discursos da identidade lhes oferecem? O nível psíquico também deve fazer parte da explicação, trata-se de uma dimensão que, juntamente com a simbólica e a social, é necessária para uma completa conceitualização da identidade. Todos esses elementos contribuem para explicar como as identidades são formadas e mantidas. (WOODWARD, 2005, p.13-15).

O entendimento dessa construção teórica sobre identidade serve para uma melhor compreensão das relações que se processam no espaço e dos mecanismos de diferenciação que se processaram na expansão urbana de Porto Alegre e que se reproduzem na Restinga. Essa relação é expressa de forma concreta pela estrutura que o bairro apresenta, bem como pela apreensão simbólica que seus moradores possuem em relação ao espaço e que são expressas nas atitudes e nos comportamentos, assim como nas falas dos educandos e ações cotidianas e o olhar dos outros percebidos sobre si mesmo. Conforme Gamalho (2010, p. 75-76): 
A área do bairro foi adquirida em 1966, sendo primeiramente denominada como Restinga e, com a criação da Primeira Unidade Vicinal da Restinga Nova, passou a ser reconhecida como Velha Restinga. Atualmente, o bairro Restinga é um dos maiores de Porto Alegre, e a Restinga Velha é onde tudo começou. A criação do bairro significou a emergência de uma situação que articulava elementos da espacialidade da conjuntura das vilas de malocas e da periferia. Junto com o morador veio a materialidade do estigma: a maloca, em que tanto a condição da habitação quanto do sujeito, o maloqueiro, constituíam uma espécie de "herança" material e simbólica que se sobrepunha à nova condição.

A ocupação do espaço, denominado Restinga, iniciou como uma "solução" urbanística na perspectiva de um planejamento tecnocrático, na década de 1960, onde o processo de remoção era baseado na higienização e valorização das áreas centrais em detrimento das periferias, gerando exclusão de determinados espaços urbanos para abrigar moradores de vilas situadas em áreas mais centralizadas de Porto Alegre. Essa ação possibilitou a formação de uma grande diversidade territorial e social criando diferentes territorialidades no bairro. Assim, o conceito de território, na escala do bairro, tornou-se o centro de significações porque reúne fenômenos os quais podemos percebê-los como estruturantes na existência material e simbólica de diferentes sujeitos e que também se fazem constituir no contexto escolar.

\section{A ESCOLA, OS SUJEITOS E SEUS COTIDIANOS TERRITORIALIZADOS}

Há no bairro Restinga, uma nítida fragmentação territorial: a mais antiga - com infraestrutura precária, com ruas estreitas e paralelas e outras sinuosas e irregulares - é chamada de Restinga Velha; a com maior infraestrutura urbana é chamada de Restinga Nova - com algumas ruas largas, com bastante comércio e acessos menores onde mora a maioria das famílias de "classe média" do bairro com residências de alvenaria, seguindo certo padrão, mas que também possui áreas com ocupações irregulares e habitações precárias; a mais nova é denominada de $5^{\mathrm{a}}$ Unidade Vicinal da Restinga possui casas populares pequenas e padronizadas, construídas pela prefeitura, mas já alteradas devido à necessidade de ampliações e carências de infraestrutura urbana; a parte correspondente ao Parque Industrial com 88 hectares (PMPA, 2012) possui 28 empresas instaladas, atuando em diversas atividades econômicas, tais como: reciclagem em plásticos e papel, produção de estandes, pavimento em cimento, móveis sob medida, placas em granito e materiais da construção civil e que sediará as instalações da Escola Técnica Federal e Unidade Hospitalar; e por fim, há um espaço onde predominam atividades rurais, com propriedades pequenas e médias que mantêm alguns aspectos do ambiente anterior à chegada dos moradores das vilas centrais. Entretanto, é no limite entre a chamada "Restinga Nova" e a "Restinga Velha", divididas pela principal via de acesso ao bairro avenida João Antônio da Silveira - que ocorrem muitos conflitos, às vezes violentos por parte de gangues que disputam o controle do narcotráfico. Junto a esta avenida, a divisa é marcada, também, pela Esplanada da Restinga, uma praça central que concentra muitas atividades socioculturais do bairro. 
Figura 1 - Praça da Esplanada da Restinga

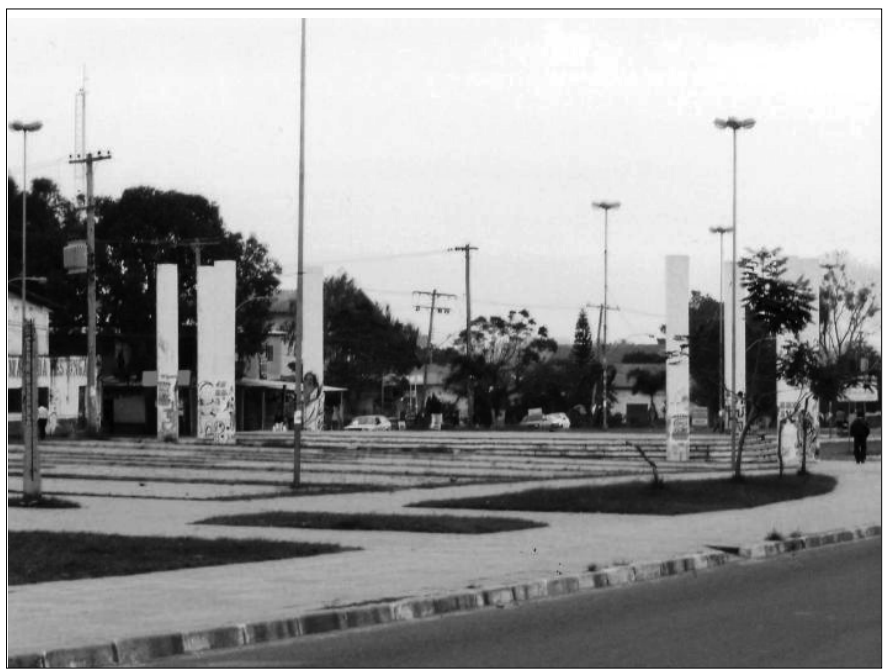

Nota: Esta praça divide a Restinga Nova da Restinga Velha e pode ser compreendida como um espaço territorializado pelo cotidiano, pois os moradores a compartilham de diversas formas: feiras, festas, teatro, encontros etc, onde identidades podem ser relativizadas em função das regras de convivência estabelecidas. É um território compartilhado pela convivência, pelas atividades de lazer e de sociabilidade. Mas também é palco de conflitos de muitas gangues. Em 2006, foi o cenário de apresentação do Programa Central da Periferia, coordenado pela apresentadora Regina Case.

O tempo marcou a construção de diferentes territórios na Restinga. Esses são percebidos pelas relações culturais e sociais vivenciadas no cotidiano do bairro e permanecem vivas, inclusive, nos sambas enredos da Escola de Samba Estado Maior da Restinga, como também de manifestações culturais do Hip Hop. As Figuras 2 e 3 demonstram estas manifestações:

Figura 2 - Fachada do prédio que abriga as instalações da Escola de Samba Estado Maior da Restinga

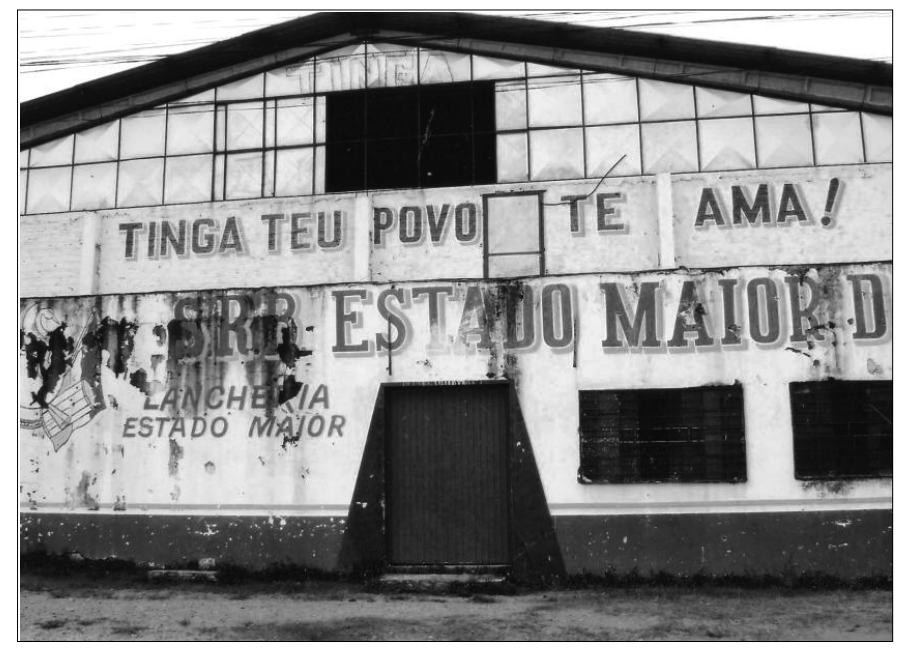

Nota: Pode-se dizer que o bairro Restinga é um espaço que ganha significação pelas relações afetivas que os sujeitos compartilham com o bairro, expressas em símbolos que as representam, como as letras de samba-enredo e manifestações do hip hop e festejos no período do carnaval. As letras das músicas da Escola Estado Maior da Restinga (com destaque para as composições de Arilson Trindade, Claudinho, e Sandrinho Gesse) frequentemente expressam a valorização do bairro e dos sujeitos (residentes da Restinga) e de suas raízes, evidenciando suas especificidades culturais, a autoimagem produzida, enfim a identidade. O lema da Escola é Tinga Teu Povo Te Ama. 
Este universo de relações foi explorado em práticas de ensino na Escola Municipal de Ensino Fundamental Professor Larry José Ribeiro Alves que possibilitaram revelar os diferentes tempos (passado, presente e futuro) e as marcas no espaço. Através de imagens e identidades, os microterritórios concebidos dentro do bairro ganham uma existência para os que compartilham dele. Esta existência vai tecendo-se a partir de condições relacionais (papéis socialmente construídos que auxiliam na construção e reconstrução de diferentes territórios) e de dinâmicas sociais e culturais que vão marcando cotidianamente o espaço (Figuras 3 e 4).

Figura 3 - Fachada da E.M.E.F. Larry e seu entorno

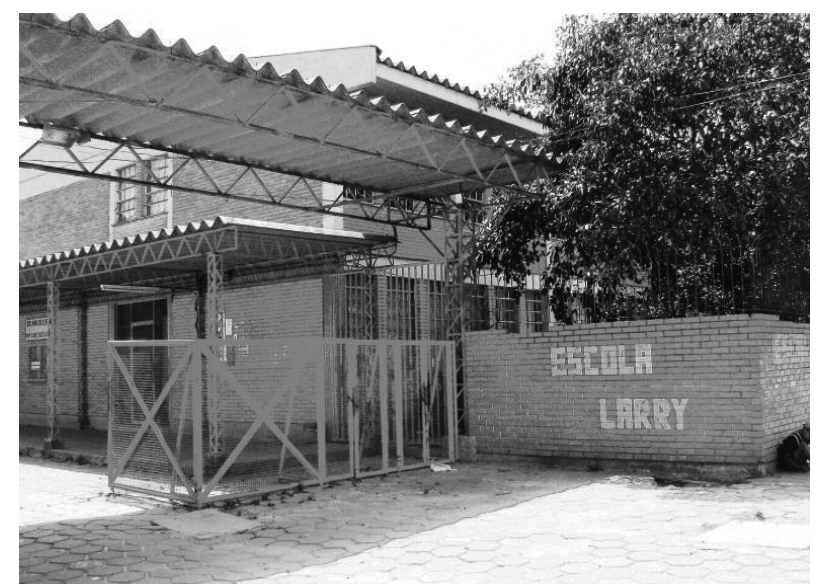

Figura 4 - Grafite presente no muro do pátio da E.M.E.F. Larry

Nota: O grafite revela uma das manifestações culturais do bairro, demonstrando nessa relação de identidade, a expressão do hip hop.

Esses aspectos tornaram-se importantes referenciais a serem trabalhados na sala de aula, particularmente no ensino de geografia, onde se percebeu que as marcas territoriais construídas no bairro eram de interesse dos jovens na escola, podendo ser exploradas no processo de ensino-aprendizagem, desacomodando posturas e criando oportunidades de transformar a realidade vivida. Por isso, articulando o mundo vivido e suas construções microterritoriais, poderemos compreender melhor as dinâmicas espaciais que criamos e transformamos constantemente. Nesse sentido, um dos caminhos metodológicos para estabelecer essa conexão foi explorar as trajetórias de vida da comunidade escolar. A partir de "falas", relatos, imagens foram estabelecidos eixos conceituais para problematizar a realidade vivida.

As "falas" correspondem à expressão de aspectos socioculturais presentes na comunidade e obtidas com base na aplicação de um roteiro de entrevista. Conforme Aigner $(2000)^{2}$, as entrevistas foram feitas com membros das comunidades locais: alunos do terceiro ciclo de formação ${ }^{3}$ que frequentam a escola há mais de dois anos; pais de

2 Os resultados da entrevistas foram divulgados na dissertação de mestrado intitulada Alfabetização em geografia e educação ambiental: construindo a cidadania em escolas voltadas a educação popular.

3 As escolas de ensino fundamental da Prefeitura Municipal de Porto Alegre possuem uma proposta pedagógica baseada em ciclos de formação que têm duração de nove anos. Este é organizado em três ciclos que visam respeitar o ritmo, o tempo, as experiências e as características da faixa etária dos alunos, contribuindo com a continuidade de suas aprendizagens durante os três anos de cada ciclo. As faixas etárias são divididas da seguinte forma: 1) I Ciclo: crianças entre 6 a 8 anos; 2) II Ciclo: pré-adolescentes ente 9 a 11 anos; 3) III Ciclo: adolescentes entre 12 a 14 anos. Os educandos que apresentam defasagem escolar, ou seja, a escolaridade não corresponde a faixa etária do ano-ciclo, são inseridos em turmas de progressão onde há uma flexibilidade maior para o temo de aprendizagem. 
alunos que moram nas proximidades da escola há mais de dois anos; membros da equipe diretiva escolar e do conselho escolar; professores que trabalham na escola há mais de dois anos. Além disso, foram feitas observações do cotidiano das comunidades.

As entrevistas visavam aos aspectos qualitativos e subjetivos, que posteriormente foram analisados e discutidos no decorrer do trabalho. Em muitos casos, não foram realizados registros no local ou na presença do entrevistado, para evitar possíveis constrangimentos; em outros, as entrevistas aproximavam-se de uma conversa informal, buscando maior aproximação e interação entre o entrevistador e o entrevistado.

O conjunto de "falas" possibilitou compreender, a partir do cotidiano de pais e alunos, dinâmicas socioculturais e diversas relações de sociabilidade existentes no bairro. Os discursos auxiliaram na percepção de conceitos que poderiam ser melhores problematizados na perspectiva pedagógica da escola. A proposta pedagógica da escola estava ancorada no complexo temático denominado "Restinga, mostra tua cara". O complexo temático é o ponto de partida para construção do currículo e é resultado da pesquisa socioantropológica que procura expressar as questões cotidianas vivenciadas pela comunidade escolar. Nessa perspectiva, conceitos como território, fronteira, urbano, rural, ambiente, cultura compõe o complexo temático a partir da problematização das "falas" da comunidade escolar. Estes conceitos passam a expressar a relação entre conceitos e temas na organização curricular da escola.

À primeira vista, imagina-se que uma escola, localizada na principal avenida da Restinga Nova, atenda basicamente a um público residente nela. Verifica-se, em contrapartida, que um número significativo de alunos das escolas reside em outras áreas periféricas do bairro: Barro Vermelho, Vila Pitinga, Vila Flor da Restinga, Vila Castelo, Vila Rocinha, Vila do Salso, Núcleo Esperança e, ainda um significativo grupo da Restinga Velha, tornando a diversidade territorial o foco de trabalho.

Boa parte dos alunos não residentes na Restinga Nova teve passagens por outras escolas situadas na Restinga Velha, tanto da rede estadual como municipal e foram estudar na Restinga Nova, porque enfrentavam problemas para transitar em locais próximos a sua moradia (em função das gangues de adolescentes ou de brigas).

Em pesquisas realizadas, com educandos e familiares residentes no bairro, ficou evidente a preocupação da comunidade com a questão da violência. Havia um forte apelo das pessoas entrevistadas para modificar este aspecto no bairro. A expectativa de muitos dos entrevistados não era simplesmente sair do bairro (o que se observa em muitas comunidades de periferia urbana), mas buscar o apoio das instituições, exigir controle e segurança nas escolas, reivindicar maior policiamento no bairro, mais iluminação nas praças, indústrias (para gerar emprego), áreas de lazer com infraestrutura para esporte, em síntese, qualificar o espaço cotidianamente com base em ações locais.

Como exemplo disso, podemos citar algumas falas de membros da comunidade escolar, colhidas durante a realização de pesquisas na E.M.E.F. Prof. Larry José Ribeiro Alves: "tem muita briga de gangues, a escola deveria mandar esses alunos embora"; "a droga destrói uma família"; " antes na escola que na rua"; "depois do muro a escola ficou melhor"; "a Direção deve trazer mais os pais para discutir a violência"; "falta segurança 
à noite"; "A população aumentou e a segurança não"; "coloco meus filhos cedo para dentro"; "fecho tudo cedo" etc.

Embora transpareça, em muitas falas, um apelo para melhoria de segurança, muitos adolescentes denunciam a discriminação por morar na Restinga. Isso foi observado em muitos relatos de alunos da escola: "sou discriminado quando estou fora do bairro"; "ninguém sabia onde ficava a Restinga"; "a Restinga está mais conhecida, as escolas de samba e os jogadores de futebol fizeram a Restinga aparecer, não é mais só um bairro de marginais"; "eu moro na Restinga, mas não sou marginal"; "a comunidade exclui sua mão de obra, o comércio só emprega parentes"; "não sinto discriminação no bairro, fora até existe"; "se a gente diz que mora na Restinga, já ficam desconfiados"; "quando vou nas festas, eu digo que moro lá em Ipanema, não sou doido de dizer que moro na Restinga".

Existe uma grande expectativa de ascensão social e de crescimento pessoal por intermédio da escola. A comunidade, de forma geral, espera que a escola possa ajudar na conquista de bons empregos, melhorando a situação socioeconômica da família. Isso se demonstra, em especial, nas falas dos pais: "estudo ninguém tira da gente, é patrimônio que jamais será perdido"; "quem não tem estudo, não tem nada"; "estudo é um meio de progredir"; "eu digo pra eles irem pra escola pra não ficar burro-velho que nem o pai"; "é importante estudar para crescer como pessoa e profissionalmente"; "quero que meus filhos estudem pra ter um bom emprego"; "hoje em dia quem não tem estudo não pega serviço nem de lixeiro"; "o sonho de todo o pai é ver o filho formado".

Embora a preparação para o trabalho tenha surgido em muitos relatos, os pais percebiam a importância da escola na construção de valores éticos e morais: "a escola tem dar apoio para os alunos, fazer com que eles tenham coragem e esforço para alcançar seus objetivos"; "quero que meu filho seja honesto e tenha caráter, sempre falo pra ele ouvir os professores"; "o que eu sonho para minha filha é que ela estude, faça cursos e que ela trabalhe e que goste do que ela estiver fazendo"; "que seja muito feliz e que com seu esforço tenha um futuro brilhante, de muito amor e que tudo que ela fizer, que faça com muito amor"; "que reflita muito e que tenha muita confiança nela mesma e em Deus"; "o caráter, os pensamentos, atitudes, realizações, felicidade, decisões, humanidade e sabedoria, tudo isso, começamos em casa e terminamos na escola".

A compreensão desses territórios proporciona uma leitura crítica dessa fragmentação vivenciada pela comunidade e possibilita ações menos excludentes, tornando o ensino de geografia um instrumento importante nesse processo de reflexão e desacomodação de atitudes. As instituições educacionais públicas passam a ter, neste contexto, um papel fundamental no fortalecimento das identidades e na constituição de espaços de formação humana. A escola em si é um espaço privilegiado que pode provocar a resistência e criar novas possibilidades de transformação da realidade vivida cotidianamente, alterando assim os rumos da organização social em escala local e promovendo a integração entre povos e culturas em escala global (globalização cooperativa ou solidária).

Na Restinga, a instituição escolar é um lugar valorizado pela comunidade, porque é vista como um dos instrumentos necessários para a ascensão social. Nesse sentido, 
a escola corresponde ao lugar com significação afetiva. Mas compreende um microterritório porque enseja disputas que se expressa em diversas formas e funções relacionadas à própria estrutura da instituição educacional do nosso país como também da comunidade onde ela está inserida. Ainda que pareça um lugar depreciado por muitos jovens, um número significativo de pais alimenta a expectativa com relação à escola e acredita que os jovens terão uma vida melhor do que a deles, se tiverem oportunidade de estudar.

Esta valorização da escola para a melhoria da qualidade de vida, observada tanto na pesquisa como no dia-a-dia em sala de aula, pode ser o ponto de partida para o desenvolvimento de práticas educadoras, pois este sentimento de prestígio pode ser canalizado no sentido de transformar o espaço escolar num lugar agradável, proporcionando a maior permanência do educando na escola, estimulando e facilitando a continuidade de seus estudos e, conseqüentemente, possibilitando novas leituras do mundo.

Nesse sentido, a escola deve ser concebida como um espaço a ser re-apropriado com a finalidade de educar para a construção de um espaço para o exercício da cidadania pela produção e socialização de saberes transformadores. A escola é paradoxal: ela liberta e aprisiona simultaneamente. A instituição escolar, voltada à educação popular, é compreendida, nessa pesquisa, como parte integrante de um sistema educacional excludente, mas, contraditoriamente, com grande capacidade de criar possibilidades de inserção e de transformação do próprio sistema que a gerou.

Surge daí uma articulação necessária: percepção/cultura e vivência/experiência. Essa relação não nega as relações de poder que, também, estão inseridas no espaço, além de seus infinitos elementos concretos e subjetivos que criam a complexidade territorial do bairro. Pensando nisso, foram discutidos, em sala de aula, além dos relatos, os projetos de organização espacial, protagonizados pelos movimentos identitários, referenciados pelos sujeitos envolvidos e seus diferentes conflitos territoriais.

\section{CONSIDERAÇÕES FINAIS}

É importante ressaltar que o trabalho desenvolvido na instituição escolar envolvida nesta pesquisa teve a pretensão de apresentar formas de resistência ao que se pode chamar de "lógica da exclusão". Ela pode ser entendida como a lógica do capital, do individualismo e da segregação, em que só os mais fortes prosperam e grandes parcelas da população ficam cada vez mais distantes dos benefícios das tecnologias e do avanço científico que se concentram junto aos centros urbanos.

Ainda que pareça uma grande contradição, é fato que é justamente nas periferias dos grandes centros urbanos (onde se encontram as tecnologias de ponta e a maior produção de novos conhecimentos científicos) que o maior número de pessoas está excluído de direitos e acessos a bens necessários à existência biológica, política e simbólica. É sabido que a migração para os grandes centros urbanos não se explica apenas pelos fatores de expulsão do meio rural e de aglomerações menores (questões fundiárias, precariedade de 
condições de vida etc.), mas pela combinação destes com os fatores de atração exercidos pelos espaços urbanos.

Na realidade, a complexidade dos espaços urbanos permite uma flexibilização maior das formas de organização, uma aceitação maior das diferenças (ainda que a intolerância, a discriminação e o preconceito sejam evidentes), criando possibilidades maiores de transformação e de resistências por estarem interligados dinamicamente e mais diretamente às redes mundiais de poder.

Essas características se refletem dentro do espaço escolar, onde são reproduzidos os mesmos conflitos. A compreensão desses processos, internalizada no cotidiano da escola, auxilia no desenvolvimento da espacialidade dos elementos que integram o espaço e a realidade que os alunos vivenciam. O estudo do espaço vivido possibilita a articulação conceitual com o território. A escala de análise pautada nos sujeitos (alunos, professores, funcionários, comunidade escolar em geral) reflete a articulação entre o local e o global. As experiências e expectativas da comunidade no bairro influenciam diretamente na dinâmica espacial, construindo as relações de poder, assim como as formas e organização geográfica. Baseado na rede de valores e de significações concretas e subjetivas, o espaço é apropriado de diferentes formas que ganham uma dinâmica identitária e um sentimento de pertencimento atribuído pelas pessoas que convivem neste espaço.

O geografar cotidiano não nega os saberes tradicionais da geografia na perspectiva da ciência moderna, mas potencializa outros olhares e ações. Professores e geógrafos negam, muitas vezes, os saberes relativos ao mundo-vivido e quando projetam seus trabalhos, posicionam-se no mundo como únicos. Edgar Morin, ao retomar necessidade de uma consciência científica, apresenta à sociedade a necessidade de cada um de nós (sujeitos e coletividades) se posicionar no mundo, olhando em direção aos outros e a nós mesmos.

No bairro Restinga, a articulação entre o olhar e a percepção do espaço vivenciado revelou especificidades que compartilham experiências singulares e mais generalizadas, ou seja, globalizadas. Esta relação produz identidades relativas à individualidade do sujeito ao mesmo tempo coletivo. Conforme Stuart Hall (2005), a identidade preenche o espaço entre o mundo pessoal e mundo o público, ou seja, "costura" nossos significados e valores próprios ao mundo social e cultural construído pela racionalidade global. Daí a importância de entender que o conhecimento construído nessa costura, torna-se fundamental para nos compreender melhor no mundo.

O sentido da educação, e em especial ensino de geografia, por sua vez, deve contribuir para essa construção e, assim, possibilitar uma sociedade menos excludente, com base na promoção de valores éticos voltados para a liberdade e para a solidariedade (PIRES, AIGNER; VEIGA, 2008). Para tanto, deve instrumentalizar aqueles para os quais tem sido negado, historicamente, o acesso ao conhecimento, gerando uma forma de exclusão social acentuada nos últimos anos pelo processo de concentração de renda e de poder, trazido pela globalização acelerada da economia.

Instrumentalizar os educandos, neste mundo "globalizado", significa proporcionar condições para transformar o espaço vivido por intermédio da operacionalização dos 
conhecimentos adquiridos conduzindo a ações libertadoras. Educar é desacomodar posturas frente ao espaço vivido e criar novas atitudes para a vida. Para tanto, os educandos precisam encontrar na escola e nas aulas de geografia um espaço propício à produção de saberes que possam levar a superação de conflitos vivenciados no cotidiano. A aproximação entre escola e comunidade oferece uma perspectiva promissora, pois sabe-se que as possibilidades de transformação e de inserção social existem e podem ser impulsionadas, com certeza, pelas práticas educativas e pelas instituições formais de ensino, que se fortalecem nas localidades, quando possuem apoio e também apoiam as comunidades atendidas.

Contudo, sabe-se que o cotidiano das escolas, porém, reflete a complexa realidade do chamado período tecno-científico-informacional (SANTOS, 1996), caracterizado, entre outras coisas, pela acelerada dissolução e construção de valores e territórios, pelo enfraquecimento aparente do poder de alguns Estados Nacionais e pela imposição de um modelo globalizante que traz consigo uma grande concentração de riquezas, seguindo-se de um processo de grande exclusão social e manifestando-se espacialmente como uma falsa contradição: a fragmentação de espaços políticos (regionalização) e a união econômica de povos e culturas pela padronização do consumo e da intensificação das relações comerciais internacionais (globalização).

Assim sendo, o entendimento de mudanças locais passa cada vez mais pelo entendimento da organização territorial, em escala global e local, e está intimamente ligado à compreensão das relações de poder político e a sua espacialização. $O$ espaço local, nesse "mundo globalizado", é o espaço de resistência e também de grandes mudanças; portanto, as práticas educativas tornam-se ainda mais importantes do que outrora para o fortalecimento das identidades locais, promovendo a inserção e combatendo a exclusão social.

O choque entre modelos de consumo e culturas, porém, cria resistências e conflitos, inseguranças e mudanças de valores, aumentando a complexidade da organização do espaço mundial e local. As teorias modernas já não dão conta da velocidade das mudanças e o aumento da complexidade do sistema de relações internacionais do modo de produção capitalista pós-industrial só traz a certeza de que todas as certezas são muito momentâneas. Atualmente, a pesquisa inserida no cotidiano escolar torna-se um necessário instrumento para romper com a sociedade excludente. A "ciência" sendo, em si própria, um discurso e, portanto, interessada, deve estar acessível para a comunidade, expondo seus interesses. Dessa forma, passa a ser incorporado ao currículo e às práticas, a relação entre pesquisa e ensino. Significa olhar para nós mesmos e para o contexto espacial que produzimos como num jogo de espelhos, ou seja, o reflexo do que percebo nada mais é do que nossas práticas cotidianas.

A reflexão sobre essas questões, por parte dos professores de geografia, torna-se de grande relevância para aqueles que pensam em construir uma prática educativa que forneça alicerces para a instrumentalização da sociedade, visando à transformação social. A escola há muito não pode ser concebida como um aparelho do Estado com o objetivo de manter o status quo, ou como um mero "espaço de reprodução" da ordem social e da ideologia da classe dominante. É claro que a prática do professor parte de uma 
visão de mundo que é produto de uma história pessoal e coletiva, mas as transformações estruturais, pelas quais estamos passando, exigem uma revisão de conceitos.

A educação, assim como a instituição escolar, não sendo neutra ou desinteressada, pode, então, romper com dominação político-cultural. Dada a especificidade, historicamente arbitrária da educação moderna, torna-se importante deixar de naturalizá-la como uma coisa essencialmente boa. A educação é uma "faca de dois gumes", pois dá poder à medida que disciplina, oferece liberdade exigindo a obediência e se permite ser consumida e ser tratada como meio para um fim apenas, na medida em que esse fim implique o consumo permanente e, portanto, a reprodução da própria educação.

Será na desconstrução dessas relações de poder que a identidade híbrida será valorizada. O espaço urbano multiplica essa dimensão relacional entre os sujeitos que vivem nestes espaços, tornando importante a tomada de consciência do lugar onde as redes de sociabilidade são vividas cotidianamente. Segundo Zilá Mesquita (1995), a consciência territorial pode ser entendida como consciência do lugar, aquele vivido cotidianamente.

Na escola, a relação identitária, ao ser problematizada, poderá transformar os códigos de conduta, as regras socioespaciais, os valores atitudinais e outras características que orientam cada sujeito no mundo. Por isso, é na identidade que está o eixo de articulação conceitual entre paisagem e territorialidade. Qualquer sujeito na relação indivíduo/ coletividade constrói um espaço concreto e subjetivo moldando formas e funções, ou seja, criando paisagens. Esta organização alimenta e é alimentada pela identidade espacial - territorialidade - contudo, múltipla e inacabada. Neste caso, as redes locais estão cada vez mais complexas e por isso torna-se a necessária uma abordagem relacional entre ensino-pesquisa para tratar as questões relativas à territorialidade e paisagem. Trata-se de repensar as escalas de trabalho e reflexão que neste caso são as microterritoriais. A partir de narrativas identitárias que demonstrem seu conteúdo heterogêneo e ambíguo, resultado dos diferentes grupos ou redes que se estabelecem no espaço, é que poderá reivindicar para si a autonomia.

Nesse sentido, não se pode manter o processo de ensino-aprendizagem distante da dialética das configurações territoriais (local e global se justapõem como simultâneos e múltiplos). A compreensão de atitudes microterritoriais pode colocar os educandos frente a frente com as diferenças, já que estas são vividas e perceptíveis porque se expressam como manifestações e delimitações territoriais. Para os educandos, há um mundo vivido, um espaço de vida cotidiano caracterizado por aquilo que Milton Santos chama de fixos e fluxos, ou seja, a casa e a escola estão interligadas por itinerários fixos e interagem com as pessoas, que expressam suas atitudes em um movimento contínuo de fluxos.

É preciso reconhecer as trajetórias de vida dos sujeitos e pautá-las na dimensão curricular da escola. O desconhecimento da história de vida de quem está na escola leva a práticas desconectadas da realidade e, consequentemente, ao desinteresse pelas atividades escolares. Mas, acima de tudo, trata da importância desse conhecimento para a autorreflexão e transformação da realidade do espaço vivido e, assim, construir outras paisagens (mais justas e solidárias). Contudo, isso necessita retomar cotidianamente a consciência territorial. 


\section{REFERÊNCIAS}

AIGNER, Carlos. Alfabetização em geografia e educação ambiental: construindo a cidadania em escolas voltadas a educação popular. Dissertação (Mestrado). Porto Alegre: UFRGS, 2002.

GAMALHO, Nola Patrícia. Remover para promover: espaço concebido e representações do espaço no bairro Restinga - Porto alegre/RS. Revista GEOgraphia (UFF), Rio de Janeiro, v. 12, n. 23, 2010.

HALL, Stuart. A identidade cultural na pós-modernidade. São Paulo: DP\&A Editora, 2005.

MAFFESOLI, Michel. A ética pós-moderna. Revista Faculdade de Educação da Universidade São Paulo. São Paulo, v. 17, jan/dez., 1991.

MESQUITA, Zilá. Do território à consciência territorial. In: MESQUITA, Z.; BRANDÃO, C. R. (Org.). Territórios do cotidiano: uma introdução a novos olhares e experiências. Porto Alegre: Ed. da UFRGS, 1995.

MORIN, Edgar. O método: a natureza da natureza. Porto Alegre: Sulina, 2003.

PIRES, Cláudia; AIGNER, Carlos; VEIGA, Amarildo. Lugar, escola e territorialidade urbana. In: UEDA, Vanda (Orgs.). A emergência da multiterritorialidade: a ressignificação da relação do humano com espaço. Porto Alegre: UFRGS \& Canoas: Ulbra, 2008.

PREFEITURA MUNICIPAL DE PORTO ALEGRE (PMPA), Secretaria Municipal de Indústria e Comércio (SMIC). Zona Sul de Porto Alegre. Disponível em: <www.portoalegre.rs.gov.br > Acesso em: 10 jan. 2012.

SANTOS, Milton. A natureza do espaço: técnica e tempo; razão e emoção. São Paulo: Hucitec, 1996.

WOODWARD, Kathryn. Identidade e diferença: uma introdução teórica e conceitual. In: SILVA, Tomaz Tadeu da. (Org.). Identidade e diferença: a perspectiva dos estudos culturais. Petrópolis RJ: Vozes, 2000.

Recebido em 19/01/2012

Aceito para publicação em 29/03/2012 